\title{
More inequality with demise of health accord
}

$\mathrm{M}$ edical leaders warn of increasing health inequality across Canada as the federal government adopts a more hands-off approach to health care.

Insufficient national leadership and mechanisms to hold provinces accountable for health system performance are longstanding barriers to health reform in Canada, experts said at a May 21 town-hall meeting in Ottawa.

"That was a weakness of the [recently expired] 2004 health accord, and unless we do the business of health reform differently in future, we're destined to repeat that failure," said Dr. Jack Kitts, CEO and president of the Ottawa Hospital.

The 2004 accord, formally titled the 10-Year Action Plan on Health, boosted federal health transfers to the provinces and territories by $\$ 41$ billion over a decade with the aim of reducing wait times, bolstering home care, improving primary and preventive care, and developing a national pharmacare strategy. But beyond modest wait time reductions in cancer care, heart surgery, hip replacement, diagnostic imaging and cataracts, the investment produced little change.

"The same document calling for the same reforms could be written today with more urgency," said Kitts. "Hospitals, drugs and doctors continue to dominate our health care spending."

The 2004 accord expired Mar. 31, but the federal government has refused to negotiate a new deal. Instead, the Conservatives handed down a funding arrangement that will see increases in

federal health transfers fixed to each province and territory's gross domestic product, with a guaranteed floor of $3 \%$ per year and without conditions on how that money is used. That means the

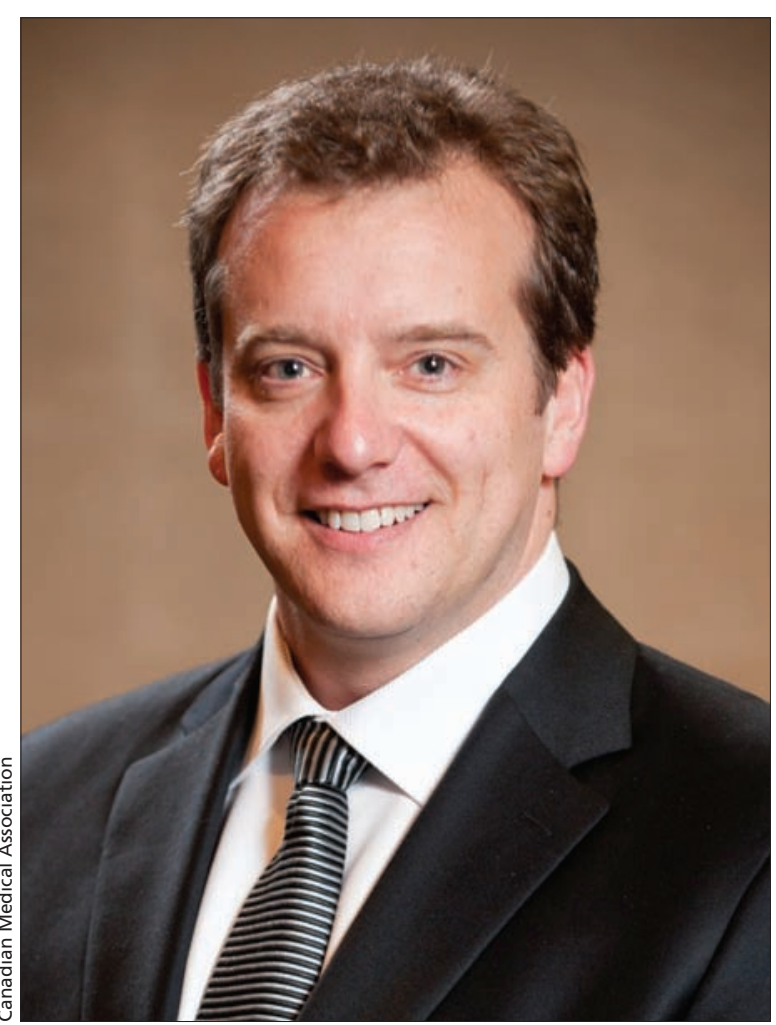

Provinces should publicly report performance on health reform, says CMA President-elect Dr. Chris Simpson. provinces and territories will receive $\$ 36$ billion less over the next 10 years (based on an annual economic growth projection of $4 \%$ ), according to research by the Council of the Federation, a body comprising Canada's 13 premiers.

According to Ray Deonandan, an epidemiologist and assistant professor of health sciences at the University of Ottawa, using economic activity as an indicator of health need seems "very weird," particularly given the link between economic disadvantage and worse health across a variety of indicators. He also notes that have-not provinces typically have higher proportions of older citizens, who may also require more health resources.

Dr. Chris Simpson, Canadian Medical Association presidentelect, expressed concern that the new arrangement may create or exacerbate disparities in care for vulnerable populations, placing unsustainable demands on provincial budgets.

"It's only a matter of time before the provinces and territories mount a renewed challenge to the federal government's moral authority to enforce the Canada Health Act," he added.

Simpson also questioned the wisdom of providing no-stringsattached transfers, as "provinces and territories have been and are resolute in resisting attempts to facilitate benchmarking for their performance against each other."

Further, "we need to stop using the absence of a national health care strategy as an excuse to continue as we are," he urged.

Simpson called on provinces to begin national collaborations on areas of shared interest, such as senior care reforms, with or without the federal government. "We have a window of opportunity to improve health care before baby boomers make peak demands in the 2020s and 2030s." - Lauren Vogel, CMAJ

CMAJ 2014. DOI:10.1503/cmaj.109-4815 